UNIVERSIDADE DE SÃO PAULO

ESCOLA DE EDUCAÇÃO FÍSICA E ESPORTE

A INFLUÊNCIA DA VARIABILIDADE DA INTENSIDADE E DO EXERCÍCIO NO TREINAMENTO DE FORÇA PARA GANHOS DE FORÇA E ÁREA DE SECÇÃO TRANSVERSA MUSCULAR

Rodrigo Monteiro da Fonseca

SÃO PAULO

2011 


\section{A INFLUÊNCIA DA VARIABILIDADE DA INTENSIDADE E DO EXERCÍCIO NO TREINAMENTO DE FORÇA PARA GANHOS DE FORÇA E ÁREA DE SECÇÃO TRANSVERSA MUSCULAR}

RODRIGO MONTEIRO DA FONSECA

Dissertação apresentada à Escola de Educação Física e Esporte da Universidade de São Paulo, como requisito parcial para obtenção do grau de Mestre em Educação Física.

ORIENTADOR: PROF.DR. CARLOS UGRINOWITSCH 